\title{
Phosphodiesterase V Inhibition Reduces Airway Responsiveness, but Does Not Improve the Beneficial Effect of Deep Inspiration
}

\author{
George Pyrgos ${ }^{a, b} \quad$ Alkis Togias ${ }^{a, b}$ Robert H. Brown ${ }^{b-d}$ \\ a Department of Medicine, Division of Allergy and Clinical Immunology, ${ }^{b}$ Department of Medicine, \\ Division of Pulmonary and Critical Care Medicine, ${ }^{C}$ Department of Anesthesiology and Critical Care Medicine \\ and ${ }^{\mathrm{d}}$ Department of Environmental Health Sciences, Johns Hopkins University, Baltimore, Md., USA
}

\section{Key Words}

Asthma Bronchodilation - Bronchoprotection .

Hyperresponsiveness

\begin{abstract}
Background: Deep inspirations (Dls) can prevent (bronchoprotection; BP) and reverse (bronchodilation; BD) methacholine (Mch)-induced bronchoconstriction, but this effect is reduced or absent in people with asthma or airways hyperresponsiveness (AHR). The mechanisms of this defect are unknown. Objective: To indirectly examine the role of guanosine $3^{\prime}, 5^{\prime}$-cyclic monophosphate (cGMP) by testing the hypothesis that the phosphodiesterase (PDE) $\mathrm{V}$ inhibitor, sildenafil, would improve Dl-induced BP in individuals with AHR. Methods: Thirty-two individuals were screened and 15 met all the inclusion/exclusion criteria (7 subjects with AHR and 8 healthy subjects). A single-dose Mch challenge inducing a $20 \%$ reduction in $\mathrm{FEV}_{1}$ in the absence of DIs was first identified. Thereafter, every study participant had 4 pairs of visits, each pair testing DI-induced BP and BD against the single-dose Mch, with no drug, or pretreatment with 25, 50 and $100 \mathrm{mg}$ of sildenafil, respectively, in consecutive order. Results: Sildenafil did not influence baseline lung function. However, in the absence of DIs, the drug caused a dose-dependent attenuation of the Mch-induced decrease in $\mathrm{FEV}_{1}$ by $17 \%$ (median value; 25 th percentile: 1,75 th percentile:
\end{abstract}

16), 35\% (-3,61) and $37 \%(13,79)$ for the $25-, 50$ - and $100-\mathrm{mg}$ doses, respectively $(p=0.0004)$. No differences between the two participant groups were found. There were no effects of sildenafil on DI-induced BP or BD. Conclusion: We infer from these results that the mechanism responsible for the defective ability of DIs to protect the airways from bronchoconstriction is unlikely to be due to dysregulation of cGMP. Of importance, a potential role for PDE $\mathrm{V}$ inhibition as a bronchoprotector treatment needs to be explored.

Copyright $\odot 2013$ S. Karger AG, Basel

\section{Introduction}

Deep inspirations (DIs) can prevent (bronchoprotection; $\mathrm{BP}$ ) and reverse (bronchodilation; BD) methacholine (Mch)-induced bronchoconstriction in healthy individuals, but their effect is reduced or absent in people with asthma [1-3]. The mechanisms behind this defect remain to be determined. In a previous report, our group attempted, with little success, to improve the BP effect of DIs using high doses of inhaled fluticasone [4], with the assumption that the loss of this effect was secondary to airway inflammation. In the current study, we aimed at addressing the role of the biochemical pathway that involves the airway smooth muscle relaxant effects of guanosine $3^{\prime}, 5^{\prime}$-cyclic monophosphate (cGMP).

\section{KARGER}

E-Mail karger@karger.com

www.karger.com/res
C 2013 S. Karger AG, Basel

0025-7931/13/0863-0243\$38.00/0
Robert H. Brown, MD, MPH

Johns Hopkins School of Public Health

Department of Environmental Health Sciences, Room E7614

615 North Wolfe Street, Baltimore, MD 21205 (USA)

E-Mail rbrown@jhsph.edu 
Airway stretch has been demonstrated as a necessary step to activate the beneficial properties of DI $[5,6]$. Airway distension depends on the forces generated during DI-induced inflation of the lungs. One factor that influences the magnitude of these forces is the change in lung volume with a DI from functional residual capacity to total lung capacity. Recent work from our laboratory suggests that there is a minimum required stretch of the airway walls that allows the airway to remain dilated even after the stretch is removed [7]. This concept is also supported by ex vivo experimentation and by in vivo animal data $[8-12]$.

Intact ability to stretch the airways in asthma is not adequate for the beneficial effects of DI to fully manifest. People with mild asthma often have complete loss of BP by DI [13] despite the fact that their ability to distend their airways with a DI is not different from healthy controls [14]. Downstream neural or biochemical processes may, therefore, be mediating the effectiveness of DI.

Stretch of smooth muscle organs such as the bladder and the esophagus leads to changes in wall tension through nitric oxide (NO)-mediated pathways $[15,16]$. Previous work from our laboratory showed that airway dilation resulting from lung inflation to relatively high pressure in a canine model was inversed to airway constriction when $N^{\mathrm{G}}$-nitro-L-arginine methyl ester, a NO synthase (NOS) blocker, was administered [10]. Physiological amounts of NO derived from constitutive NOS (cNOS) modulate underlying pulmonary function and are associated with baseline pulmonary function and decreased airways responsiveness [17]. Recent animal studies suggest an important role for the cNOS isoforms in controlling airways hyperresponsiveness (AHR) [18-21]. NO deriving from constitutive neuronal NOS (type I) plays a major role in the mediation of nonadrenergic, noncholinergic BD in humans [22-24]. NO increases soluble guanylyl cyclase (sGC) which in turn increases cGMP leading to smooth muscle relaxation. Phosphodiesterase (PDE) V degrades cGMP [25]. Thus, inhibitors of PDE V, such as sildenafil, lead to elevated levels of cGMP, and cause smooth muscle relaxation [26, 27]. In a lung-slice model, NO-induced relaxation of the airways was enhanced by selective inhibitors of cGMP-specific PDE V [28].

The study described herein was designed with the primary objective to test the hypothesis that the PDE V inhibitor, sildenafil, improves the DI-induced BP responses in individuals with AHR. The choice of primary outcome was based on our previous work showing a stronger relationship between BP (over BD) and AHR [4]. Secondary objectives included testing the hypotheses that sildenafil would also increase the BP effect of DI in healthy individuals as well as the BD effects of DI in individuals with AHR and healthy subjects.

\section{Materials and Methods}

\section{Subjects}

A total of 32 individuals were screened for the study and 15 met all inclusion/exclusion criteria. Inclusion criteria for both subject groups (subjects with AHR and the healthy control group) were male sex (females were excluded because sildenafil is only approved for males), age 18-50 years, resting systolic blood pressure $\geq 100 \mathrm{~mm} \mathrm{Hg}$ and resting heart rate $\geq 55$ beats per minute. Exclusion criteria for both groups included use of antihypertensive treatment or any history of cardiovascular disease. Additionally, current smokers and former smokers with $>10$ pack-years of smoking as well as endurance athletes (running $>20$ miles/week or equivalent exercise) were excluded, the latter individuals because we have previously shown that they do not bronchoconstrict to inhaled Mch even in the absence of DI [29].

Subjects with AHR had to have reported upper and/or lower respiratory symptoms in the 12 months prior to the study in the absence of upper respiratory infections, have had at least 2 positive allergy skin prick tests, an $\mathrm{FEV}_{1} \geq 70 \%$ predicted, and a positive conventional, multidose $\mathrm{Mch}$ inhalation challenge $\left(\mathrm{PC}_{20} \leq 25 \mathrm{mg} / \mathrm{ml}\right)$. All of these subjects had to demonstrate a bronchoprotective effect of DI (bronchoprotective index) less than $40 \%$ (see below for methodology and definition). Exclusion criteria for this group included persistent respiratory symptoms suggesting uncontrolled asthma. Subjects on short-acting bronchodilators were asked to withhold these medications for at least $8 \mathrm{~h}$ prior to Mch challenge. One subject was on a long-acting bronchodilator inhaler. He was asked to withhold that medication for $48 \mathrm{~h}$ prior to Mch challenge.

Healthy subjects had to have no history of respiratory illness or recurrent upper or lower respiratory symptoms, no more than one positive skin prick test, an $\mathrm{FEV}_{1}>80 \%$ predicted, and an $\mathrm{FEV}_{1} /$ FVC ratio no less than $95 \%$ predicted. Also, they had to have $<10 \%$ reduction in $\mathrm{FEV}_{1}$ after receiving the top dose $(25 \mathrm{mg} / \mathrm{ml})$ of $\mathrm{Mch}$ in a conventional, multidose challenge. The protocol was approved by the Johns Hopkins University IRB. Informed, written consent was obtained from each subject.

Study Design

Screening

This included a general medical examination with focus on respiratory history, physical examination, skin prick testing with a panel of common aeroallergens, and baseline spirometry followed by a conventional Mch challenge. For spirometry, we used Hankinson (NHANES III) predicted values [30].

\section{Evaluation of the Beneficial Effects of DI}

The assessment of DI-induced BD was performed using multiple modified single-dose Mch challenges on separate days, as previously described [31]. At every single-dose challenge, after baseline spirometry, study participants were instructed to abstain from taking DIs for $20 \mathrm{~min}$. At the end of this period, a single-dose 
Fig. 1. Schema of protocol (not to scale). On the study visits that involved the administration of sildenafil, following a brief history and physical examination, spirometry was performed and either nothing or a single oral dose of sildenafil was administered. Subjects were asked to remain in the laboratory for 70 min after sildenafil administration. After $70 \mathrm{~min}$, spirometry was repeated. Subsequently, the study participant entered the above-described 20-min quiet breathing (no deep breaths) period after which the assessment of DI-induced BD (a) or BP (b) was conducted (see text).

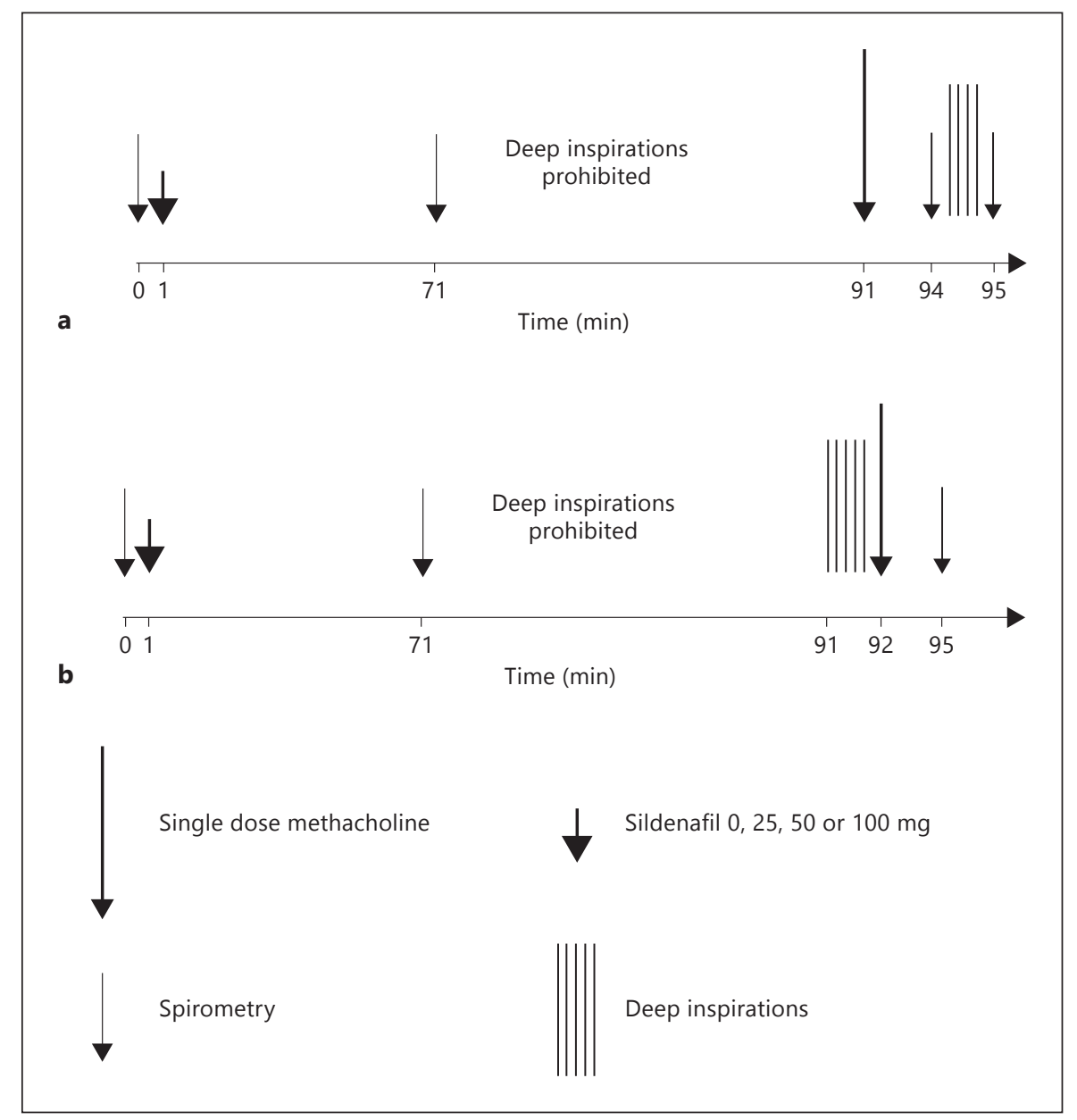

Mch challenge (starting at $0.025 \mathrm{mg} / \mathrm{ml}$ ) was delivered with five tidal inspirations from a deVilbiss 646 nebulizer attached to a model 2A Rosenthal-French dosimeter (Laboratory for Applied Immunology Inc., Fairfax, Va., USA). Three minutes later, a single full spirometric maneuver was performed and the degree of airways obstruction was calculated by comparing baseline to post$\mathrm{Mch} \mathrm{FEV}_{1}$. If the Mch-induced reduction in $\mathrm{FEV}_{1}$ was not greater than $20 \%$, the participant was invited to return on a separate day for another single-dose Mch challenge, using the next highest single-dose of Mch (e.g. $0.075 \mathrm{mg} / \mathrm{ml}$ ). This process was continued with additional single-dose challenges $(0.25,0.75,2.5,7.5 \mathrm{mg} / \mathrm{ml})$ on separate days, until the single dose inducing $\geq 20 \%$ reduction in $\mathrm{FEV}_{1}$ was delivered. At the challenge where $20 \%$ or greater reduction in $\mathrm{FEV}_{1}$ was achieved, the participant was instructed to continue the procedure by taking 4 DIs immediately after the single post-Mch spirometry. Another spirometric maneuver was performed immediately after the 4 DIs to calculate the degree to which the participant was able to reverse the Mch-induced airway obstruction (fig. 1a). By measuring the difference between the post-Mch $\mathrm{FEV}_{1}$ and the FEV 1 obtained after the 4 DIs, we were able to calculate a measure of $\mathrm{BD}$ induced by the DIs, which we termed the BD index. This measure, which has been previously described [1], is calculated as follows:

PDE V Inhibition Reduces Airway

Responsiveness
$\mathrm{BD}$ index $=\left[1-\left(\left[1-\left(\left[\mathrm{FEV}_{1}\right.\right.\right.\right.\right.$ after Mch and after DI $] /\left[\mathrm{FEV}_{1}\right.$ baseline $])] /\left[1-\left(\left[\mathrm{FEV}_{1}\right.\right.\right.$ after $\left.\mathrm{Mch}\right] /\left[\mathrm{FEV}_{1}\right.$ baseline])])] $\times 100$.

To simplify the above equation, the BD index is derived from two components, the reduction in $\mathrm{FEV}_{1}$ from baseline after Mch and after DIs, and the reduction in $\mathrm{FEV}_{1}$ from baseline after Mch, but before DIs. Also, a BD index of $100 \%$ refers to a DI that reversed all bronchoconstriction to the Mch challenge.

On a separate day, the same single Mch dose used to achieve a $20 \%$ reduction in $\mathrm{FEV}_{1}$ was again administered after 20 min of quiet breathing. However, prior to the single-dose $\mathrm{Mch}$, the subject was instructed to take 5 DIs to prevent the Mch-induced obstruction. By measuring the difference between the Mch-induced reduction in $\mathrm{FEV}_{1}$ on the day no DIs were taken (fig. 1a) versus the day 5 DIs were taken prior to the challenge (fig. 1b), we obtained a measure of BP induced by the series of DIs, which we termed the BP index. This measure, which has been previously described [1], is calculated as follows:

$$
\begin{aligned}
\mathrm{BP} \text { index }= & {\left[1-\left(\left[1-\left(\left[\mathrm{FEV}_{1} \text { after DIs and after } \mathrm{Mch}_{\mathrm{B}}\right] /\left[\mathrm{FEV}_{1}\right.\right.\right.\right.\right.} \\
& \text { baseline } \left.\left.\left._{\mathrm{B}}\right]\right)\right] /\left[1-\left(\left[\mathrm{FEV}_{1} \text { after } \mathrm{Mch}_{\mathrm{A}}\right] /\left[\mathrm{FEV}_{1}\right. \text { base- }\right.\right. \\
& \text { line } \left.\left.\left.\left.\left._{\mathrm{A}}\right]\right)\right]\right)\right] \times 100 .
\end{aligned}
$$


In other words, the BP index is derived from two components, the Mch-induced reduction in $\mathrm{FEV}_{1}$ from baseline on the day 5 DIs preceded the single-dose Mch challenge $(\mathrm{B})$ and the Mch-induced reduction in $\mathrm{FEV}_{1}$ from baseline on the day no DIs were taken prior to the single-dose Mch challenge $\left({ }_{\mathrm{A}}\right)$. Also, a BP index of $100 \%$ refers to a DI that prevented all bronchoconstriction to the Mch challenge.

\section{Sildenafil Dosing}

Subjects underwent 8 study visits within a period of 1-3 months. After the BP and BD effects of DI were determined, the two study visits described in figure $1 \mathrm{a}$ and $\mathrm{b}$ were repeated 4 times on separate days, first with no pretreatment and then with sildenafil pretreatment. On the study visits that involved the administration of sildenafil, following a brief history and physical examination, spirometry was performed and a single oral dose of sildenafil was administered beginning from the lowest dose $(25 \mathrm{mg})$. Subjects were asked to remain in the laboratory for $70 \mathrm{~min}$ after sildenafil administration and vital signs were recorded at 35 and $70 \mathrm{~min}$. Caffeinated drinks were prohibited. After $70 \mathrm{~min}$, spirometry was repeated. Subsequently, the study participant entered the above-described 20-min quiet-breathing (no deep breaths) period after which the assessment of DI-induced BD and BP was conducted as described above (fig. 1a, b). For safety reasons and since the effects of sildenafil on lung function or AHR were unknown at the time, we chose to start at the lowest dose and administer the next dose in increasing order on subsequent visits. Consequently, every study participant had 8 study visits (fig. 1a, b) receiving no sildenafil on 2 consecutive visits, $25 \mathrm{mg}$ on 2 consecutive visits, $50 \mathrm{mg}$ on 2 consecutive visits and $100 \mathrm{mg}$ on the last 2 visits.

\section{Data Analysis}

Data analysis was performed using JMP 7.0.1 software (SAS Institute Inc., Cary, N.C., USA). Because of the limited number of subjects, we took a conservative approach and made no assumptions about the distribution of the data and used nonparametric statistics. We used the Wilcoxon and the Kruskal-Wallis tests to compared the baseline pulmonary function measurements between the subjects with AHR and the healthy subjects, the effect of sildenafil on lung function (change in $\mathrm{FEV}_{1}$ between predosing and $70 \mathrm{~min}$ postdosing), the effects of sildenafil on the single-dose Mch-induced decrease in $\mathrm{FEV}_{1}$ from baseline, and the effects of sildenafil on the $\mathrm{BP}$ and $\mathrm{BD}$ indices.

To test the effects of dose and the effect of sildenafil on the response to Mch regardless of DI, we performed simple linear regression analyses to evaluate the relationship between the attenuation in the single-dose Mch-induced decrease in $\mathrm{FEV}_{1}$ and the $\mathrm{BP}$ and $\mathrm{BD}$ indices separately for the group with AHR and the healthy groups.

To examine the effects of the change in baseline $\mathrm{FEV}_{1}$ with increasing sildenafil doses, we performed two-way ANOVA, one with the BP index and the other with the BD index as the dependent variable. The independent variables in both models were the percent change in the response to Mch with increasing sildenafil dose as a continuous independent variable, and the sildenafil dose as a categorical independent variable. Significance was accepted at $\mathrm{p} \leq 0.05$.

An a priori statistical analysis plan also included an interim analysis. The study was terminated early because not only did we not obtain the expected effect size, in fact we did not even see a
Table 1. Characteristics of study participants

a Participants with AHR

\begin{tabular}{lllllll}
\hline $\begin{array}{l}\text { AHR } \\
\text { subject }\end{array}$ & Age & $\begin{array}{l}\mathrm{FEV}_{1} \% \\
\text { pred. }\end{array}$ & $\begin{array}{l}\mathrm{FVC}^{2} \% \\
\text { pred. }\end{array}$ & $\begin{array}{l}\mathrm{FEV}_{1} / \\
\mathrm{FVC}\end{array}$ & $\begin{array}{l}\mathrm{PC}_{20} \\
\mathrm{mg} / \mathrm{ml}\end{array}$ & Meds. \\
\hline 1 & 21 & 89 & 87 & 86 & 7.15 & 1 \\
2 & 27 & 80 & 94 & 72 & 0.13 & $1,2,3,4$ \\
3 & 21 & 111 & 108 & 85 & 8.9 & - \\
4 & 27 & 72 & 86 & 68 & 0.24 & 1 \\
5 & 23 & 91 & 101 & 74 & 1.47 & $1,3,5$ \\
6 & 26 & 93 & 89 & 85 & 13.6 & - \\
7 & 20 & 104 & 106 & 80 & 2.048 & - \\
Mean $\pm \mathrm{SD}$ & $24 \pm 3$ & $91 \pm 13$ & $96 \pm 9$ & $79 \pm 7$ & & \\
\hline
\end{tabular}

b Healthy study participants

\begin{tabular}{lccclll}
\hline $\begin{array}{l}\text { Healthy } \\
\text { subject }\end{array}$ & Age & $\begin{array}{l}\mathrm{FEV}_{1} \% \\
\text { pred. }\end{array}$ & $\begin{array}{l}\mathrm{FVC}_{0} \% \\
\text { pred. }\end{array}$ & $\begin{array}{l}\mathrm{FEV}_{1} / \\
\mathrm{FVC}\end{array}$ & $\begin{array}{l}\mathrm{PC}_{20} \\
\mathrm{mg} / \mathrm{ml}\end{array}$ & Meds. \\
\hline 1 & 22 & 96 & 101 & 81 & $>25$ & - \\
2 & 22 & 92 & 97 & 80 & $>25$ & - \\
3 & 21 & 121 & 116 & 88 & $>25$ & - \\
4 & 19 & 98 & 102 & 81 & $>25$ & - \\
5 & 26 & 85 & 106 & 68 & $>25$ & - \\
6 & 21 & 86 & 94 & 78 & $>25$ & - \\
7 & 39 & 87 & 87 & 83 & $>25$ & - \\
8 & 20 & 80 & 87 & 77 & $>25$ & - \\
Mean $\pm \mathrm{SD}$ & $24 \pm 6$ & $93 \pm 13$ & $99 \pm 10$ & $79 \pm 6$ & & \\
\hline
\end{tabular}

Meds. = Respiratory medications; 1 = inhaled beta-agonist bronchodilators; 2 = inhaled corticosteroids; 3 = nasal corticosteroids; $4=$ leukotriene receptor antagonists; $5=$ antihistamines.

trend towards increased DI-induced BP or BD in the presence of sildenafil. Given that we did not even see a trend, if we were to use the interim data to calculate power for a subsequent study, the number of subjects sufficient to demonstrate a significant result would be approaching infinite. In other words, it was futile to continue the study.

\section{Results}

Seven subjects with AHR and 8 healthy individuals were enrolled in the study. On the basis of inclusion criteria, all subjects with AHR had clinical symptoms compatible with asthma and several were using asthma medications. Their demographic data are shown in table 1a and $b$. There were no differences in baseline pulmonary function measurements between the subjects with AHR and the healthy subjects with regards to their $\mathrm{FEV}_{1}(\mathrm{p}=$ $0.76)$, FVC $(p=0.59)$ or their $\mathrm{FEV}_{1} / \mathrm{FVC}(\mathrm{p}=0.87)$. 
The median single-dose Mch concentration identified in the screening phase of the study as the dose required to reduce $\mathrm{FEV}_{1}$ by $20 \%$ when DIs were withheld was 18.05 $\mathrm{mg} / \mathrm{ml}$ in the healthy group and $0.75 \mathrm{mg} / \mathrm{ml}$ in the AHR group. In the screening phase, the median change in $\mathrm{FEV}_{1}$ after the single-dose Mch challenge when DIs were withheld was $-33 \%$ (median value; 25 th percentile: $-44,75$ th percentile: -31$)$ and $-31 \%(-44,-25)$ for the subjects with AHR and the healthy subjects, respectively. In the screening phase of the study, the BP index was $26 \%(9,60)$ and $41 \%(15,74)$ for the subjects with AHR and the healthy subjects, respectively, and the BD index was $28 \%(11,34)$ and $55 \%(18,72)$ for the subjects with AHR and the healthy subjects, respectively.

Sildenafil, at any dose, did not influence lung function (data derived from the spirometry that was obtained 70 min after dosing) in either group of participants (change in $\mathrm{FEV}_{1}$ between predosing and 70 min postdosing: subjects with AHR, $\mathrm{p}=0.99$ and healthy group, $\mathrm{p}=$ $0.99)$. However, the drug caused a dose-dependent attenuation in the single-dose Mch-induced decrease in $\mathrm{FEV}_{1}$ from baseline. Specifically, in subjects with AHR, sildenafil attenuated the Mch-induced decrease in $\mathrm{FEV}_{1}$ by $9 \%$ $(3,64), 45 \%(-12,61)$ and $44 \%(18,59)$ for the $25-, 50$ - and 100-mg doses, respectively, compared to Mch challenge without sildenafil pretreatment $(\mathrm{p}=0.03)$. In the healthy subjects, sildenafil also attenuated the Mch-induced decrease in $\mathrm{FEV}_{1}$ by $18 \%(-5,64), 25 \%(0,64)$ and $37 \%(10$, 57) for the 25-, 50- and 100-mg doses, respectively, compared to Mch challenge without sildenafil pretreatment $(p=0.02)$. There was no difference in the percent attenuation of the Mch effect between the two participant groups at any dose of sildenafil (for the 25-mg dose, $p=0.91$, for the 50 -mg, $\mathrm{p}=0.95$, and for the 100 -mg dose, $\mathrm{p}=0.63$ ). The percent changes in $\mathrm{FEV}_{1}$ from baseline by the singledose Mch challenge, at each dose of sildenafil and for each group of participants are presented in figure 2 .

The primary outcome of our study was the effect of sildenafil on the BP index. We found no significant relationships between the increasing doses of sildenafil and the BP index ( $p=0.17$ and $\mathrm{p}=0.35$ for the subjects with AHR and healthy groups, respectively; table 2). Similarly, we found no relationship between sildenafil dose and the BD index ( $p=0.52$ and $p=0.98$ for the AHR and healthy groups, respectively; table 3 ). It is interesting to note that a numeric trend towards reduction in $\mathrm{BP}$ and $\mathrm{BD}$ by sildenafil was observed in subjects with AHR, which was practically absent in the healthy group. This resulted in greater differences between the two groups in both the $\mathrm{BP}$ and the BD indices: at the 100-mg sildenafil dose, the

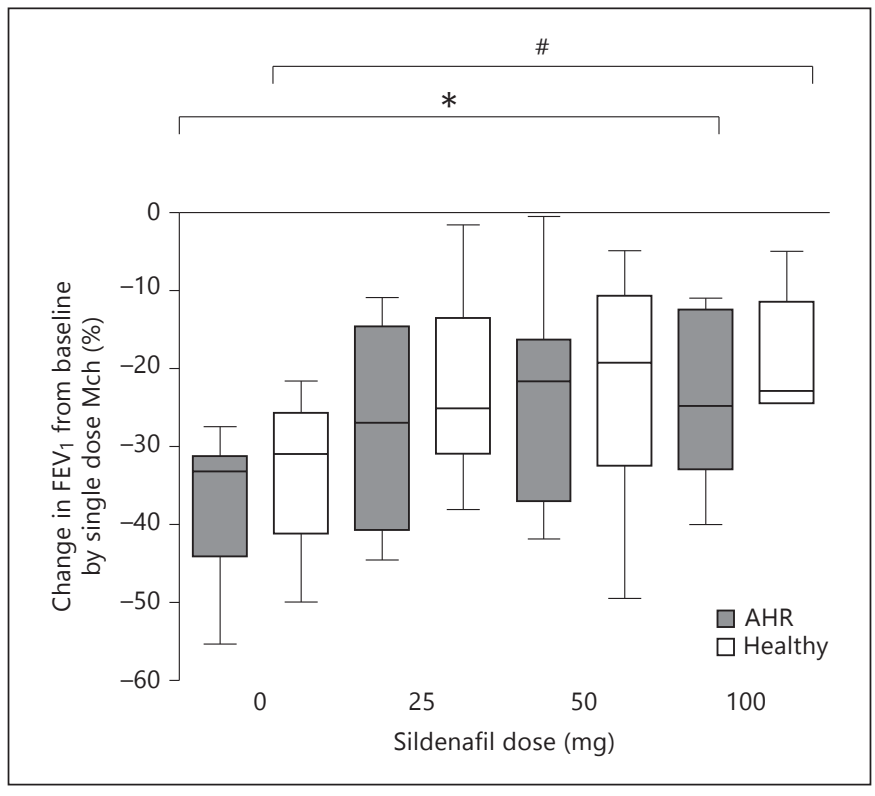

Fig. 2. Box plot graph of the percent fall in $\mathrm{FEV}_{1}$ to the single-dose Mch challenge when DIs were withheld for the subjects with AHR (grey bars) and the healthy subjects (white bars) for each dose of sildenafil. There was an increasing attenuation in the fall in $\mathrm{FEV}_{1}$ to the single-dose Mch challenge with increasing doses of sildenafil for both the subjects with AHR $\left({ }^{*} \mathrm{p}=0.03\right)$ and the healthy subjects ( ${ }^{\#} \mathrm{p}=0.02$; Wilcoxon rank-sum test).

Table 2. The effect of sildenafil on the BP index

\begin{tabular}{ccll}
\hline $\begin{array}{l}\text { Sildenafil } \\
\text { dose, mg }\end{array}$ & $\begin{array}{l}\text { AHR } \\
\text { participants }\end{array}$ & $\begin{array}{l}\text { Healthy } \\
\text { participants }\end{array}$ & $\begin{array}{l}\text { All } \\
\text { participants }\end{array}$ \\
\hline 0 & $26(9,60)$ & $41(15,74)$ & $36(13,69)$ \\
25 & $-13(-131,42)$ & $43(25,64)$ & $28(-19,44)$ \\
50 & $19(-46,44)$ & $59(19,80)$ & $39(-29,70)$ \\
100 & $-27(-59,33)$ & $30(-30,37)$ & $26(-37,32)$ \\
\hline
\end{tabular}

Median values are presented with 25th and 75th percentiles in parentheses.

Table 3. The effect of sildenafil on the BD index

\begin{tabular}{rlll}
\hline $\begin{array}{l}\text { Sildenafil } \\
\text { dose, mg }\end{array}$ & $\begin{array}{l}\text { AHR } \\
\text { participants }\end{array}$ & $\begin{array}{l}\text { Healthy } \\
\text { participants }\end{array}$ & $\begin{array}{l}\text { All } \\
\text { participants }\end{array}$ \\
\hline 0 & $28(11,34)$ & $55(18,72)$ & $33(13,63)$ \\
25 & $13(-21,42)$ & $57(14,69)$ & $28(-10,60)$ \\
50 & $7(-2,30)$ & $49(11,86)$ & $18(4,61)$ \\
100 & $13(-6,26)$ & $51(20,69)$ & $29(-2,52)$ \\
\hline
\end{tabular}

Median values are presented with 25 th and 75 th percentiles in parentheses. 
median BP indices in the AHR and the healthy groups were -27 and $30 \%(p=0.52)$, respectively; for the BD indices, the median values were 13 and $51 \%(p=0.08)$, respectively.

Our data raised the question of whether the apparent attenuation of the Mch-induced bronchoconstriction by sildenafil had an impact on the lack of an effect of sildenafil on the DI-induced BP and BD. To address this question, we examined whether there was any relationship between the attenuation in the single-dose Mch-induced decrease in $\mathrm{FEV}_{1}$ and the $\mathrm{BP}$ and $\mathrm{BD}$ indices. In simple regression analyses, in the subjects with $\mathrm{AHR}$, we found a significant negative relationship between the percent change in the single-dose Mch-induced decrease in $\mathrm{FEV}_{1}$ and the BP $\left(\mathrm{r}^{2}=0.57, \mathrm{p}<0.0001\right)$ or the BD $\left(\mathrm{r}^{2}=0.33\right.$, $\mathrm{p}=0.002)$ indices, implying that $\mathrm{DI}$-induced $\mathrm{BP}$ and $\mathrm{BD}$ were diminished in association with the diminished effects of Mch. These relationships were not significant in the healthy group (for the $\mathrm{BP}$ index, $\mathrm{p}=0.08$; for the $\mathrm{BD}$ index, $\mathrm{p}=0.13$ ).

Since we found a significant correlation between the $\mathrm{BP} / \mathrm{BD}$ indices and the change in the single-dose Mchinduced decrease in $\mathrm{FEV}_{1}$ from baseline in the group with AHR, we examined the effect of the sildenafil dose on $\mathrm{BP}$ and $\mathrm{BD}$ controlling for the change in the singledose Mch-induced decrease in $\mathrm{FEV}_{1}$ from baseline. We performed two-way ANOVA, one with the BP index and the other with the BD index as the dependent variable. The independent variables in both models were the percent change in the response to Mch with increasing sildenafil dose as a continuous independent variable, and the sildenafil dose as a categorical independent variable. For the BP index in the group with AHR, the overall model was significant $(p=0.01)$. Controlling for the dose of sildenafil in the subjects with AHR, we found a significant relationship between the percent change in the single-dose Mch-induced decrease in $\mathrm{FEV}_{1}$ and the BP index $(p=0.02)$. However, controlling for the percent change in the $\mathrm{FEV}_{1}$ response to Mch with sildenafil, the dose of sildenafil was not significantly related to the change in the BP index $(\mathrm{p}=0.41)$. For the BD index, the two-way ANOVA model was not significant in the AHR group $(\mathrm{p}=0.72)$.

\section{Discussion}

To our knowledge, this is the first study examining the effects of a PDE V inhibitor on the function of DI; as part of the study, we also tested the effect of PDE V inhibition on airway responsiveness measured by Mch challenge. We conducted this study to address the hypothesis that cGMP may play a role in the beneficial effects of DI. We tried to address this hypothesis in an indirect manner, using a PDE $\mathrm{V}$ inhibitor (sildenafil) to reduce the natural degradation of cGMP. The finding that sildenafil caused a dose-dependent protection from the direct bronchoconstrictive effects of Mch regardless of the study participants' condition confounded our ability to test our hypotheses. However, this represents a novel observation that requires attention.

We and others have previously shown that bronchoconstriction by Mch inhalation can be induced to a similar degree in individuals with AHR and in healthy controls in the absence of DI [32], and that a single-dose of $\mathrm{Mch}$, after $20 \mathrm{~min}$ of quiet breathing, can be used to assess the ability of DI to either protect from or reverse the Mch effects $[1,13]$. Using this well-established methodology, we achieved an almost identical reduction in $\mathrm{FEV}_{1}(>30 \%)$ in individuals with AHR and healthy controls, the required median concentration of the single Mch dose being $18.05 \mathrm{mg} / \mathrm{ml}$ in the healthy group and $0.75 \mathrm{mg} / \mathrm{ml}$ in the group of study participants with conventionally determined AHR. At the highest dose of sildenafil, we observed an approximately $40 \%$ attenuation of the Mch-induced fall in $\mathrm{FEV}_{1}$ compared to the challenge in which no sildenafil was administered. We did not observe a difference in this attenuation between the subjects with AHR and the healthy groups at any dose of sildenafil (fig. 2). The protective effect of sildenafil against Mch cannot be explained by an effect on baseline lung function, which remained unaffected by any sildenafil dose. This study was not designed to explore whether sildenafil can improve $\mathrm{FEV}_{1}$ because participants with AHR, although they had a history of respiratory symptoms compatible with asthma, were asymptomatic and under good control with an average $\mathrm{FEV}_{1} 96 \%$ predicted.

The effect of sildenafil on the response to Mch was not an expected finding and, therefore, the protocol did not include conventional multidose Mch provocations that would allow the use of common outcomes such as the $\mathrm{PC}_{20}$. It is, therefore, impossible to interpret the magnitude of the effect we observed with a $\mathrm{PC}_{20}$ outcome in mind. This could be the objective of a follow-up study, where sildenafil would be used to reduce Mch responsiveness; in such a study the design should focus on a $\mathrm{PC}_{20}$ outcome obtained through multiple dose Mch provocations.

There are limited and conflicting published works examining the effects of PDE V inhibition on airway reac- 
tivity, in animal models. Sousa et al. [33] showed that sildenafil relaxed carbachol-contracted and OVA-sensitized rat airways in a concentration-dependent manner. In guinea pigs, Toward et al. [34] showed that sildenafil treatment did not affect histamine-induced bronchoconstriction. Clayton et al. [35] showed that sildenafil had no effect on the levels of TNF- $\alpha$, IL- 4 and IL-5 in the BAL of OVA-challenged mice. These differences may be due to the different agonist or species used. Our data are consistent with those of Sousa et al. [33] who found protection against a cholinergic stimulus.

For our primary outcome, the BP index, as well as for the secondary outcome, the BD index, we found no effect of sildenafil at any dose (tables 2, 3). Both indices appeared to worsen with sildenafil particularly in the subjects with AHR, although these effects did not reach statistical significance. To examine whether this 'worsening' of the $\mathrm{BP}$ and $\mathrm{BD}$ indices with sildenafil was secondary to the drug-induced change in the bronchoconstrictive response to $\mathrm{Mch}$, we constructed multivariate models which included the sildenafil dose and the percent change in the Mch-induced effects on $\mathrm{FEV}_{1}$. After controlling for the change in the Mch response, sildenafil had no significant effect on the BP and BD indices. This analysis needs to be interpreted with caution because our small sample size substantially reduces the statistical power to detect independent effects of sildenafil on DI-induced BP or BD. We infer from these results that while sildenafil attenuated the Mch-induced bronchoconstriction when DIs were withheld, it did not change the ability of DIs to either protect from or to reverse Mch-induced bronchoconstriction. Notably, we have previously found that the BP and BD effects of DI become more evident when the Mchinduced bronchoconstriction in the absence of DI is of substantial magnitude [31]. The dependence of the effects of DI on the magnitude of bronchoconstriction cannot only explain the trends for worsening of the $\mathrm{BP}$ and $\mathrm{BD}$ effects by sildenafil in this study, but may have also masked any evidence of improvement in BP and BD. In the absence of any trend, however, the latter possibility is remote.

Sildenafil's inability to improve the beneficial effects of DI in individuals with AHR raises serious doubts as to whether cGMP dysregulation plays a role in the dysfunction of DI in AHR and asthma. These doubts are further strengthened by the fact that, in the absence of DIs, sildenafil did induce BP against Mch, but this effect was of equal magnitude in individuals with AHR and the healthy controls. If the ineffectiveness of DI in AHR and asthma was due to reduced production or rapid degrada- tion of cGMP, one would have expected sildenafil to at least partially restore the DI effects. On the other hand, if the problem lay in airway smooth muscle's resistance to the relaxation effects of cGMP, sildenafil would not have been as effective in protecting the airways from Mch in the study participants with AHR compared to the healthy controls.

Even if our results are not supportive of the role of cGMP in the beneficial effects of DI, we cannot eliminate the possibility that endogenous NO plays a role in these effects. Perez-Zoghbi et al. [28] studied the effects of NO donors on agonist-induced airway contraction and $\mathrm{Ca}^{2+}$ signaling of airway smooth muscle cells (SMC) in lung slices. They found that NO-induced SMC relaxation was mediated by two main mechanisms: (1) a cGMP-dependent mechanism in which $\mathrm{NO}$ binds to and activates soluble guanylate cyclase to generate cGMP, or (2) a cGMPindependent mechanism in which a functional alteration of protein (i.e. activation) occurs via nitrosylation of thiol groups $[28,36,37]$. By administering sildenafil we assume to have bypassed the NO induction of cGMP, although we did not obtain any measurements of cGMP to relate changes of this mediator to the inhibitory effects of sildenafil on the Mch-induced bronchoconstriction. We cannot rule out a cGMP-independent NO mechanism.

One limitation of the study was the sample size. The number of subjects in each group was small ( $\mathrm{n}=7$ and $\mathrm{n}=$ 8 for the subjects with AHR and the healthy group, respectively). This raises the possibility that the study was insufficiently powered to detect a difference in $\mathrm{BP}$ or $\mathrm{BD}$ if there was a real difference. However, our a priori statistical analysis plan also included an interim analysis. The study was terminated early because not only did we not obtain the expected effect size, but we also did not even see a trend towards increased DI-induced BP in the presence of sildenafil, as depicted in table 2; and the same observation was made for DI-induced BD (table 3). Given that we did not even see a trend, if we were to use the interim data to calculate power for a subsequent study, the number of subjects sufficient to demonstrate a significant result would be approaching infinite. In other words, it was futile to continue the study.

In summary, sildenafil significantly reduced the response to a single dose of Mch in individuals with AHR as well as in healthy participants to a similar extent. However, it did not improve the DI-induced BP or BD effects in the subjects with AHR across the range of doses tested. We infer from these results that the mechanism responsible for the diminution or loss of the ability of DI to protect the airways from Mch-induced bronchoconstric- 
tion or to reverse bronchoconstriction in people with AHR (including patients with asthma) is unlikely to be due to dysregulation of cGMP. On the other hand, our data raise the possibility that PDE V inhibition may be of value in the management of asthma as an add-on bronchoprotective agent, especially in view of some data indicating that long-acting beta-adrenergic agonists may lose their protective ability against induced bronchoconstriction over time [38]. This possibility requires further exploration.

\section{Financial Disclosure and Conflicts of Interest}

G.P. was recipient of the George Behrakis Hellenic Fellowship in Respiratory Allergy at the Johns Hopkins Asthma and Allergy Center. This work was supported by the National Institutes of Health, grant No. RO1HL61277, R01HL62698, RO1HL10342, 1F32HL086179-01 and ES 003819 .

\section{References}

1 Scichilone N, Permutt S, Togias A: The lack of the bronchoprotective and not the bronchodilatory ability of deep inspiration is associated with airway hyperresponsiveness. Am J Respir Crit Care Med 2001;163:413419.

-2 Scichilone N, Pygros G, Kapsali T, Anderlind C, Brown RH, Permutt S, Togias A: Airways hyperresponsiveness and the effects of lung inflation. Int Arch Allergy Immunol 2001;124: 262-266.

3 Scichilone N, Togias A: The role of lung inflation in airway hyperresponsiveness and in asthma. Curr Allergy Asthma Rep 2004;4:166174.

4 Scichilone N, Permutt S, Bellia V, Togias A: Inhaled corticosteroids and the beneficial effect of deep inspiration in asthma. Am J Respir Crit Care Med 2005;172:693699.

5 Fredberg J: Frozen objects: small airways, big breaths, and asthma. J Allergy Clin Immunol 2000;106:615-624.

6 Gunst S, Wu M: Plasticity of airway smooth muscle stiffness and extensibility: role of length-adaptive mechanisms. J Appl Physiol 2001;90:741-749.

7 Pyrgos G, Scichilone N, Togias A, Brown RH: Bronchodilation response to deep inspirations in asthma is dependent on airway distensibility and air trapping. J Appl Physiol 2011;110:472-479.

-8 Slats AM, Janssen K, van Schadewijk A, van der Plas DT, Schot R, van den Aardweg JG, de Jongste JC, Hiemstra PS, Mauad T, Rabe $\mathrm{KF}$, Sterk PJ: Bronchial inflammation and airway responses to deep inspiration in asthma and chronic obstructive pulmonary disease. Am J Respir Crit Care Med 2007;176: 121-128.

9 Gunst SJ, Shen X, Ramchandani R, Tepper RS: Bronchoprotective and bronchodilatory effects of deep inspiration in rabbits subjected to bronchial challenge. J Appl Physiol 2001;91:2511-2516.

10 Brown RH, Mitzner W: Airway response to deep inspiration: role of nitric oxide. Eur Respir J 2003;22:57-61.
Brown RH, Mitzner W: Airway response to deep inspiration: role of inflation pressure. J Appl Physiol 2001;91:2574-2578.

12 Brown RH, Mitzner W: Duration of deep inspiration and subsequent airway constriction in vivo. J Asthma 2003;40:119-124.

13 Kapsali T, Permutt S, Laube B, Scichilone N, Togias A: The potent bronchoprotective effect of deep inspiration and its absence in asthma. J Appl Physiol 2000;89:711-720.

14 Brown RH, Scichilone N, Mudge B, Diemer F, Permutt S, Togias A: High resolution computed tomographic evaluation of airways distensibility and the effects of lung inflation on airway caliber in healthy subjects and individuals with asthma. Am J Respir Crit Care Med 2001;163:994-1001.

15 Jiang Y, Bhargava V, Mittal RK: Mechanism of stretch-activated excitatory and inhibitory responses in the lower esophageal sphincter. Am J Physiol Gastrointest Liver Physiol 2009; 297:G397-G405.

16 Wei B, Chen Z, Zhang X, Feldman M, Dong XZ, Doran R, Zhao BL, Yin WX, Kotlikoff MI, Ji G: Nitric oxide mediates stretch-induced $\mathrm{Ca}^{2+}$ release via activation of phosphatidylinositol 3-kinase-Akt pathway in smooth muscle. PLoS One 2008;3:e2526.

17 Silkoff PE, Sylvester JT, Zamel N, Permutt S: Airway nitric oxide diffusion in asthma: role in pulmonary function and bronchial responsiveness. Am J Respir Crit Care Med 2000; 161:1218-1228

18 De Sanctis GT, MacLean JA, Hamada K, Mehta S, Scott JA, Jiao A, Yandava CN, Kobzik L, Wolyniec WW, Fabian AJ, Venugopal CS, Grasemann H, Huang PL, Drazen JM: Contribution of nitric oxide synthases 1,2 , and 3 to airway hyperresponsiveness and inflammation in a murine model of asthma. J Exp Med 1999;189:1621-1630.

19 Feder LS, Stelts D, Chapman RW, Manfra D, Crawley Y, Jones H, Minnicozzi M, Fernandez X, Paster T, Egan RW, Kreutner W, Kung TT: Role of nitric oxide on eosinophilic lung inflammation in allergic mice. Am J Respir Cell Mol Biol 1997;17:436-442.
20 Samb A, Pretolani M, Dinh-Xuan AT, Ouksel H, Callebert J, Lisdero C, Aubier M, Boczkowski J: Decreased pulmonary and tracheal smooth muscle expression and activity of type 1 nitric oxide synthase (nNOS) after ovalbumin immunization and multiple aerosol challenge in guinea pigs. Am J Respir Crit Care Med 2001;164:149-154.

21 Ten Broeke R, Folkerts G, Leusink-Muis T, Van der Linde HJ, Villain M, Manion MK, De Clerck F, Blalock JE, Nijkamp FP: Calcium sensors as new therapeutic targets for airway hyperresponsiveness and asthma. Faseb J 2001; 15:1831-1833.

22 Belvisi MG, Stretton CD, Yacoub M, Barnes PJ: Nitric oxide is the endogenous neurotransmitter of bronchodilator nerves in humans. Eur J Pharmacol 1992;210:221-222.

23 Ellis JL, Undem BJ: Inhibition by L-NG-nitro-L-arginine of nonadrenergic-noncholinergic-mediated relaxations of human isolated central and peripheral airway. Am Rev Respir Dis 1992;146:1543-1547.

24 Fischer A, Hoffmann B: Nitric oxide synthase in neurons and nerve fibers of lower airways and in vagal sensory ganglia of man: correlation with neuropeptides. Am J Respir Crit Care Med 1996;154:209-216.

25 Raeburn D, Souness JE, Tomkinson A, Karlsson JA: Isozyme-selective cyclic nucleotide phosphodiesterase inhibitors: biochemistry, pharmacology and therapeutic potential in asthma. Prog Drug Res 1993;40:9-32.

26 Nijkamp FP, Folkerts G: Nitric oxide and bronchial hyperresponsiveness. Arch Int Pharmacodyn Ther 1995;329:81-96.

27 Pelligrino DA, Wang Q: Cyclic nucleotide crosstalk and the regulation of cerebral vasodilation. Prog Neurobiol 1998;56:1-18.

28 Perez-Zoghbi JF, Bai Y, Sanderson MJ: Nitric oxide induces airway smooth muscle cell relaxation by decreasing the frequency of agonist-induced $\mathrm{Ca}^{2+}$ oscillations. J Gen Physiol 2010;135:247-259.

29 Scichilone N, Morici G, Marchese R, Bonanno A, Profita M, Togias A, Bonsignore MR: Reduced airway responsiveness in nonelite runners. Med Sci Sports Exerc 2005;37:2019-2025. 
30 Hankinson JL, Odencrantz JR, Fedan KB: Spirometric reference values from a sample of the general U.S. population. Am J Respir Crit Care Med 1999;159:179-187.

-31 Scichilone N, Kapsali T, Permutt S, Togias A: Deep inspiration-induced bronchoprotection is stronger than bronchodilation. Am J Respir Crit Care Med 2000;162:910-916.

-32 Skloot G, Permutt S, Togias AG: Airway hyperresponsiveness in asthma: a problem of limited smooth muscle relaxation with inspiration. J Clin Invest 1995;96:2393-2403.
33 Sousa CT, Brito TS, Lima FJ, Siqueira RJ, Magalhaes PJ, Lima AA, Santos AA, Havt A: Sildenafil decreases rat tracheal hyperresponsiveness to carbachol and changes canonical transient receptor potential gene expression after antigen challenge. Braz J Med Biol Res 2011;44:562-572.

34 Toward TJ, Smith N, Broadley KJ: Effect of phosphodiesterase-5 inhibitor, sildenafil (Viagra), in animal models of airways disease. Am J Respir Crit Care Med 2004;169:227234.

35 Clayton RA, Dick CA, Mackenzie A, Nagasawa M, Galbraith D, Hastings SF, MacKenzie SJ: The effect of selective phosphodiesterase inhibitors, alone and in combination, on a murine model of allergic asthma. Respir Res 2004;5:4.
6 Gaston B, Singel D, Doctor A, Stamler JS: Snitrosothiol signaling in respiratory biology. Am J Respir Crit Care Med 2006;173:11861193.

37 Saraiva RM, Hare JM: Nitric oxide signaling in the cardiovascular system: implications for heart failure. Curr Opin Cardiol 2006;21:221228.

38 Bhagat R, Kalra S, Swystun VA, Cockcroft DW: Rapid onset of tolerance to the bronchoprotective effect of salmeterol. Chest 1995; 108:1235-1239. 